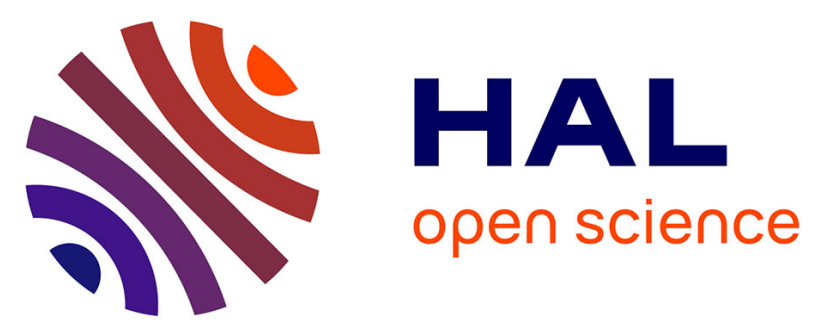

\title{
An Overview of Methods using Reduced-Ordered Transformation Matrices for Fault-Tolerant Control of 5-phase Machines with an Open Phase
}

Duc Tan Vu, Ngac Ky Nguyen, Eric Semail

\section{- To cite this version:}

Duc Tan Vu, Ngac Ky Nguyen, Eric Semail. An Overview of Methods using Reduced-Ordered Transformation Matrices for Fault-Tolerant Control of 5-phase Machines with an Open Phase. 20th IEEE International Conference on Industrial Technology (ICIT 2019), Feb 2019, Melbourne, Australia. pp.1557-1562, 10.1109/ICIT.2019.8755106 . hal-02142425

\section{HAL Id: hal-02142425 \\ https://hal.science/hal-02142425}

Submitted on 28 May 2019

HAL is a multi-disciplinary open access archive for the deposit and dissemination of scientific research documents, whether they are published or not. The documents may come from teaching and research institutions in France or abroad, or from public or private research centers.
L'archive ouverte pluridisciplinaire HAL, est destinée au dépôt et à la diffusion de documents scientifiques de niveau recherche, publiés ou non, émanant des établissements d'enseignement et de recherche français ou étrangers, des laboratoires publics ou privés. 


\title{
An Overview of Methods using Reduced-Order Transformation Matrices for Fault-Tolerant Control of 5-phase Machines with an Open Phase
}

\author{
Duc Tan Vu, IEEE, Student Member, Ngac Ky Nguyen, IEEE, Member, and Eric Semail, IEEE, Member \\ Univ. Lille, Arts et Metiers ParisTech, Centrale Lille, HEI, EA 2697 - L2EP -Laboratoire d'Electrotechnique et d'Electronique de \\ Puissance, F-59000 Lille, France \\ E-mail: \{ductan.vu; ngacky.nguyen; eric.semail\}@ensam.eu
}

\begin{abstract}
This paper studies control strategies using modified transformation matrices when five-phase machines operate in oneopen-phase faults. The basic idea of these methods is to maintain the rotating field under asymmetrical conditions as the same as in healthy condition by determining new transformation matrices. The dimension of the new matrices is equal to the number of remaining healthy phases in post-fault conditions. There have been different ways to determine the new transformation matrices applied for different types of five-phase machines in recent decades. In this study, an overview and analyses on these methods will be presented. In addition, advantages and drawbacks of these control strategies are clarified by numerical results.
\end{abstract}

Keywords- reduced-order transformation matrices; 5-phase machines; open-phase faults; fault-tolerant control; back-EMF waveform; current references; torque control

\section{INTRODUCTION}

Multiphase machines have been used in many applications in recent decades because of their advantages such as low torque pulsation, fault tolerance, adequacy to low voltage supply and reduced per phase power rating [1], [2]. The design, modeling and control strategies in healthy mode of operation are analyzed in [3] The most common faults, which occur in electrical machine drives, are open-circuited faults of stator windings of the machine and power converters [4]. Many strategies have been proposed to determine optimal current references to maximize torque with given copper losses when one or more phases of the machines are open-circuited. In [5], strategies for four, five, six and seven-phase induction machines have been proposed to determine optimal current references to maintain the magnetomotive force in degraded mode the same as in healthy condition. However, these methods in [5] deal with only fundamental components of current.

In this paper, methods using reduced-order transformation matrices for fault-tolerant control of 5-phase machines in one open phase faults will be analyzed. Several papers [6]-[13] consider only sinusoidal back-EMF machines imposed by fundamental harmonic currents while paper [14] dealing with non-sinusoidal back-EMF machines proposes an injection of the third harmonic currents. In fact, [15] introduces the use of third harmonic components of current to five-phase permanent magnet motor drives with quasi-rectangular back EMFs in an open phase fault. However, high torque ripples still exist in [15] even when the speed is controlled perfectly. The present paper aims at giving a general view and verifying the applicability of methods using adjusted transformation matrices in fault-tolerant control.

It is organized as follows: section II describes the basic model of a 5-phase machine; in section III, the analysis of control strategies using reduced-order transformation matrices in a single open-circuit fault is demonstrated.

\section{FIVE-PHASE MACHINE MODELING}

To identify the machine model, these following assumptions are considered: 5-phase windings are equally shifted and wyeconnected; the machines with sinusoidal or trapezoidal backEMFs are considered; the saturation of the magnetic circuits is not considered in the calculation of the back-EMFs and fluxes; and no reluctance effect.

Clarke and Park transformations are applied to convert the machine parameters from natural $\left(i_{a}, i_{b}, i_{c}, i_{d}, i_{e}\right)$ frame to $\alpha-\beta$ $\left(i_{\alpha 1}, i_{\beta 1}, i_{\alpha 3}, i_{\beta 3}, i_{0}\right)$ and $\mathrm{d}-\mathrm{q}$ frames $\left(i_{d 1}, i_{q 1}, i_{d 3}, i_{q 3}, i_{0}\right)$ as expressed in equations (1-4). In $\alpha-\beta$ and $d-q$ frames, the real fivephase machine is equivalent to three fictitious machines (the first machine, the second machine and the homopolar machine). Each fictitious machine consists of a given group of harmonic components [16]. It is assumed that the fundamental component is considered in the first fictitious machine while the third harmonic component is in the second fictitious machine. Other higher harmonic components are neglected. The zero-sequence current is zero $\left(i_{0}=0\right)$ because of the wye-connected winding; therefore, it cannot contribute to torque generation [17]-[19]

$$
\begin{aligned}
& {\left[\begin{array}{l}
i_{\alpha 1} \\
i_{\beta 1} \\
i_{\alpha 3} \\
i_{\beta 3} \\
i_{0}
\end{array}\right]=\left[\boldsymbol{T}_{\text {clarke }}\right]\left[\begin{array}{l}
i_{a} \\
i_{b} \\
i_{c} \\
i_{d} \\
i_{e}
\end{array}\right] ; \quad\left[\begin{array}{l}
i_{d 1} \\
i_{q 1} \\
i_{d 3} \\
i_{q 3} \\
i_{0}
\end{array}\right]=\left[\boldsymbol{T}_{\text {Park }}\right]\left[\boldsymbol{T}_{\text {clarke }}\right]\left[\begin{array}{l}
i_{a} \\
i_{b} \\
i_{c} \\
i_{d} \\
i_{e}
\end{array}\right]} \\
& {\left[\boldsymbol{T}_{\text {clarke }}\right]=\frac{2}{5}\left[\begin{array}{ccccc}
1 & \cos (\delta) & \cos (2 \delta) & \cos (2 \delta) & \cos (\delta) \\
0 & \sin (\delta) & \sin (2 \delta) & -\sin (2 \delta) & -\sin (\delta) \\
1 & \cos (2 \delta) & \cos (\delta) & \cos (\delta) & \cos (2 \delta) \\
0 & -\sin (2 \delta) & \sin (\delta) & -\sin (\delta) & \sin (2 \delta) \\
1 / \sqrt{2} & 1 / \sqrt{2} & 1 / \sqrt{2} & 1 / \sqrt{2} & 1 / \sqrt{2}
\end{array}\right]}
\end{aligned}
$$


$\left[\boldsymbol{T}_{\text {Park }}\right]=\left[\begin{array}{ccccc}\cos \theta & \sin \theta & 0 & 0 & 0 \\ -\sin \theta & \cos \theta & 0 & 0 & 0 \\ 0 & 0 & \cos 3 \theta & \sin 3 \theta & 0 \\ 0 & 0 & -\sin 3 \theta & \cos 3 \theta & 0 \\ 0 & 0 & 0 & 0 & 1\end{array}\right]$

where $\left[\boldsymbol{T}_{\text {clarke }}\right]$ and $\left[\boldsymbol{T}_{\text {Park }}\right]$ are the Clarke and Park transformation matrices in healthy operation; $\delta=2 \pi / 5$ is the spatial phase shift angle; $\theta$ is the electrical angle of the machine.

\section{Fault-tolerant Control Methods Using ReduCED- ORDER TRANSFORMATION MATRICES IN DEGRADED MODE}

\section{A. Overview of the recent methods}

In healthy mode, the three subspaces $\alpha_{1}-\beta_{1}, \alpha_{3}-\beta_{3}$ and zerosequence associated respectively to the first, third and fifth harmonics are orthogonal to each other, which makes the control currents in these subspaces independent. Therefore, constant torque is easy to produce even if the electromotive forces contain the first, third and fifth harmonics. When phase $a$ is open-circuited (Fig. 1), the first harmonic of current interacts with all the harmonics of electromotive forces. As a result, an asymmetric condition in the rotating field appears and torque pulsations are produced. The imposed current references of healthy mode are often unsuitable in this case; hence, these current references need to be modified in degraded modes [20]. The basic idea of these methods is to preserve the sinusoidal M.M.F under asymmetrical conditions. In [6], H. Ryu et al. introduces new transformation matrices for five-phase PMSM machines according to the concept that every harmonic component of the current and voltage, which can contribute to the torque positively, can be equivalently represented as dc components even under asymmetrical fault conditions. Therefore, the fundamental currents in d-q frame are kept constant as in heathy case with the new transformation matrices. H. Guzmán et al. in [7], [8] proposes new transformation matrices for 5-phase induction machines to preserve symmetrical models of resistive, leakage inductance and back-EMF with timeinvariant coefficients in asymmetrical fault conditions. In [9], [10], B. Tian et al. constructs a model based on the concept similar to the studies in [7], [8] for 5-phase PMSM machines using sliding mode control to eliminate the speed pulsation. In [11], [12], $\mathrm{H}$. Zhou et al. develops new orthogonal reduced-order transformation matrices derived by the fault-tolerant references. These studies use a remedial field-oriented control (RFOC). In [13], a control strategy is proposed by A. Seck et al. for a permanent magnet synchronous generator with single open phase by applying Particle Swarm Optimization to find elements of a new transformation matrix. All researches above have not considered the nonsinusoidal back-EMF machines as well as non-sinusoidal current references. In those methods, only fundamental currents cannot eliminate torque ripples with the non-sinusoidal back-EMFs. Thus, G. Liu et al. in [14] proposes a new model for non-sinusoidal back-EMF machines. The torque ripples caused by the third harmonic air-gap flux is analyzed and eliminated by imposing third harmonic currents in the rotating frame. The next section analyzes these methods with more details and a five-phase machine described in Table 1 is used for validations.

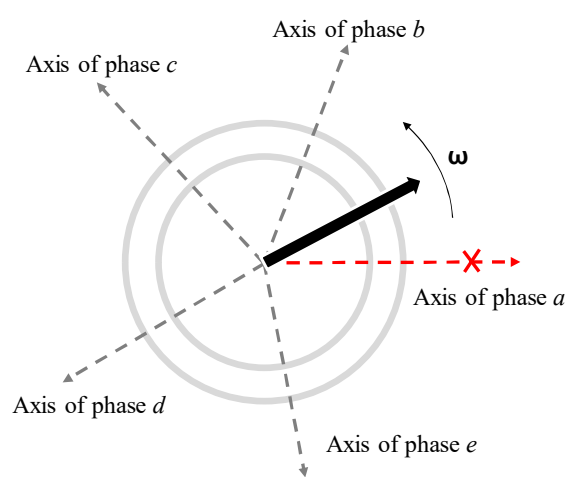

Fig. 1. Asymmetrical condition of the rotating field of a five-phase machine when phase $a$ is open-circuited

TABLE I. ELECTRICAL PARAMETERS OF CONVERTER AND MACHINE

\begin{tabular}{|l|c|}
\hline \multicolumn{1}{|c|}{ Parameter } & Value \\
\hline Stator resistance $R(\Omega)$ & 1.4 \\
\hline Phase inductance $L(\mathrm{mH})$ & 10.1 \\
\hline Mutual inductance $M_{1}(\mathrm{mH})$ & 3.1 \\
\hline Mutual inductance $M_{2}(\mathrm{mH})$ & -1.05 \\
\hline Mutual inductance $M_{3}(\mathrm{mH})$ & -5.3 \\
\hline Number of pole pairs p & 3 \\
\hline $\begin{array}{l}\text { Speed-normalized amplitude of } 1^{\text {st }} \text { harmonic back-EMF } E_{m 1} \\
\text { (V/rad/s) }\end{array}$ & 1 \\
\hline $\begin{array}{l}\text { Speed-normalized amplitude of } 3^{\text {rd }} \text { harmonic back-EMF } E_{m 3} \\
(\mathrm{~V} / \mathrm{rad} / \mathrm{s})\end{array}$ & 0.32 \\
\hline
\end{tabular}

\section{B. Categorization of reduced-order transformation matrix methods}

When phase $a$ is opened, the current of phase $a$ is equal to zero; hence, the Clarke transformation matrix from equation (3) becomes $\left[\boldsymbol{T}_{\text {clarke }}^{\prime}\right]$ as expressed in equation (5). The coupling between fundamental current and the third harmonic current is shown in equation (6).

$\left[\boldsymbol{T}_{\text {Clarke }}^{\prime}\right]=\frac{2}{5}\left[\begin{array}{cccc}\cos (\delta) & \cos (2 \delta) & \cos (2 \delta) & \cos (\delta) \\ \sin (\delta) & \sin (2 \delta) & -\sin (2 \delta) & -\sin (\delta) \\ \cos (2 \delta) & \cos (\delta) & \cos (\delta) & \cos (2 \delta) \\ -\sin (2 \delta) & \sin (\delta) & -\sin (\delta) & \sin (2 \delta) \\ 1 / \sqrt{2} & 1 / \sqrt{2} & 1 / \sqrt{2} & 1 / \sqrt{2}\end{array}\right]$

$i_{a}=0 \rightarrow i_{\alpha 1}=-i_{\alpha 3}$

The first, third and fifth row vectors of matrix [ $\left.\boldsymbol{T}_{\text {clarke }}^{\prime}\right]$ in equation (5) are no longer orthogonal to each other. Consequently, the third harmonics of current cannot make a rotating field independently of the first ones; therefore, the third components are the consequences of the first harmonic currents, leading to uncontrolled current and torque ripples. A new transformation matrix $\left[\boldsymbol{T}_{\text {clarke }}^{1}\right]$ needs to be determined with its dimension equal to the number of remaining healthy phases ( 4 by 4 ) as shown in equation (7). By using matrix $\left[\boldsymbol{T}_{\text {clarke }}^{1}\right]$, the currents of healthy phases in natural frame are projected onto the space $\alpha \beta z 0$ including fundamental stationary plane $\alpha-\beta\left(i_{\alpha}, i_{\beta}\right)$, subspace $z\left(i_{z}\right)$ and zero-sequence subspace $\left(i_{0}\right)$. To control the currents in new subspaces independently (no coupling between these two 
subspaces), the new fundamental plane $\alpha-\beta$ needs to be orthogonal to subspace $z$ even when $i_{z}$ is imposed to zero. It means that the first 3 row vectors of the new transformation matrix $\left[\boldsymbol{T}_{\text {clarke }}^{1}\right]$ must be perpendicular to one another. The orthogonality of the fourthrow vector of $\left[\boldsymbol{T}_{\text {clarke }}^{1}\right]$ to other row vectors is not mandatory since the zero-sequence current $\left(i_{0}\right)$ is obviously zero due to the wyeconnected winding.

$$
\left[\begin{array}{l}
i_{\alpha} \\
i_{\beta} \\
i_{z} \\
i_{0}
\end{array}\right]=\left[\boldsymbol{T}_{\text {Clarke }}^{1}\right]\left[\begin{array}{l}
i_{b}^{\prime} \\
i_{c}^{\prime} \\
i_{d}^{\prime} \\
i_{e}^{\prime}
\end{array}\right]
$$

where $i_{b}^{\prime}, i_{c}^{\prime}, i_{d}^{\prime}, i_{e}^{\prime}$ are the new phase currents in natural frame of the five-phase machine.

There are several ways to find the new transformation matrix $\left[\boldsymbol{T}_{\text {clarke }}^{1}\right]$ to preserve sinusoidal currents in $\alpha-\beta$ frame, leading to constant currents in $\mathrm{d}-\mathrm{q}$ frame in single open phase fault. It means that currents $i_{\alpha}$ and $i_{\beta}$ form a circle as shown in Fig. 2. Five methods using new transformation matrices in faulty modes will be analyzed in this section and summarized in Table 2 . In methods (1-4), a new Park transformation matrix in equation (8) is used to convert currents and back EMFs into d-q frame, considering only fundamental components. Method (5) applies an extra matrix in equation (20) for the third harmonic components.

$\left[\boldsymbol{T}_{\text {Park }}^{1}\right]=\left[\begin{array}{cccc}\cos \theta & \sin \theta & 0 & 0 \\ -\sin \theta & \cos \theta & 0 & 0 \\ 0 & 0 & 1 & 0 \\ 0 & 0 & 0 & 1\end{array}\right]$

(1) Method 1

The method in [6] is proposed for a sinusoidal back-EMF fivephase PMSM with a new transformation matrix $\left[\boldsymbol{T}_{\text {Clarke }}^{\mathbf{1}}\right]$ as shown in equation (9) by eliminating the third row of equation (5). The reason for this elimination is the coupling between the first and third harmonic currents as expressed in equation (6). For the sake of simplicity, all elements of the fifth-row vector are set to 1 without loss of orthogonality. Afterwards, the first row is adjusted by adding a coefficient $x$ with the aim of respecting the orthogonality of matrix $\left[\boldsymbol{T}_{\text {clarke }}^{1}\right]$ and adjusting the symmetry of back-EMFs in degraded modes. Indeed, the first three row vectors in equation (9) are always orthogonal to each other regardless of the value of $x$ because their dot products are always equal to zero.

TABLE 2. SUMMARY OF METHODS USING REDUCED-ORDER TRANSFORMATION MATRICES

\begin{tabular}{|c|c|c|c|c|}
\hline Method & References & $\boldsymbol{x}$ & Applied Machines & $\begin{array}{c}\text { Orthog- } \\
\text { onality }\end{array}$ \\
\hline 1 & {$[6]$} & 0.25 & Sinusoidal back-EMF PMSM & Yes \\
\hline 2 & {$[7]-[10]$} & -1 & $\begin{array}{c}\text { Induction Machine in [7], [8] } \\
\text { and Non-sinusoidal back-EMF } \\
\text { PMSM in [9], [10] }\end{array}$ & No \\
\hline 3 & {$[11],[12]$} & -- & Sinusoidal back-EMF PMSM & Yes \\
\hline 4 & {$[13]$} & -- & Sinusoidal back-EMF PMSG & No \\
\hline 5 & {$[14]$} & -1 & Non-sinusoidal back-EMF PMSM & No \\
\hline
\end{tabular}

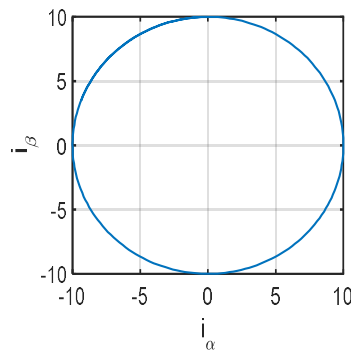

Fig. 2. The current references in fundamental $\alpha-\beta$ frame in post-fault conditions with any value of $x$ in methods 1 and 2

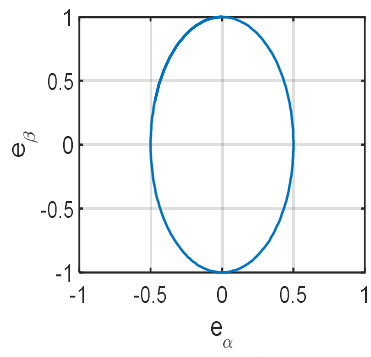

(a) $x=0.25$

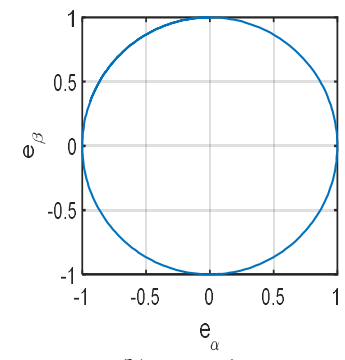

(b) $x=-1$
Fig. 3. The normalized fundamental back EMFs in $\alpha-\beta$ frame with different values of $x$ in methods 1 and 2

However, the first and fourth row vectors of $\left[\boldsymbol{T}_{\text {clarke }}^{\mathbf{1}}\right]$ are perpendicular only when $x$ equals to 0.25 . In addition, the expression of current $i_{\alpha}$ in equation (10) shows that coefficient $x$ is unable to affect the projection of current onto fundamental $\alpha-\beta$ frame since the sum of remaining healthy phase currents is always zero. However, there is an asymmetrical waveform of back EMFs in the new frame $\alpha-\beta$ as shown in Fig. 3a. The reason is that the sum of back EMFs in healthy phases is not equal to zero. Therefore, from equation (11), the value of $x$ affects the symmetrical characteristic of the back EMFs.

$$
\begin{aligned}
& {\left[\boldsymbol{T}_{\text {clarke }}^{1}\right]=\frac{2}{5}\left[\begin{array}{cccc}
(\cos \delta+x) & (\cos (2 \delta)+x) & (\cos (2 \delta)+x) & (\cos (\delta)+x) \\
\sin \delta & \sin (2 \delta) & -\sin (2 \delta) & -\sin (\delta) \\
-\sin (2 \delta) & \sin \delta & -\sin (\delta) & \sin (2 \delta) \\
1 & 1 & 1 & 1
\end{array}\right]} \\
& i_{\alpha}=\frac{2}{5}\left\{i_{b}^{\prime} \cos \delta+i_{c}^{\prime} \cos 2 \delta+i_{d}^{\prime} \cos 2 \delta+i_{e}^{\prime} \cos \delta+x\left(i_{b}^{\prime}+i_{c}^{\prime}+i_{d}^{\prime}+i_{e}^{\prime}\right)\right\} \\
& e_{\alpha}=\frac{2}{5}\left\{e_{b}^{\prime} \cos \delta+e_{c}^{\prime} \cos 2 \delta+e_{d}^{\prime} \cos 2 \delta+e_{e}^{\prime} \cos \delta+x\left(e_{b}^{\prime}+e_{c}^{\prime}+e_{d}^{\prime}+e_{e}^{\prime}\right)\right\}
\end{aligned}
$$

\section{(2) Method 2}

The method in [7]-[10], developed from [6], is applied for five-phase induction and permanent magnet machines with coefficient $x$ in equation (9) equal to -1 . In [7], [8], for an induction machine, the projections of currents, voltages and back EMFs onto the new fundamental frame $\alpha-\beta$ are obtained with the symmetrical characteristic. The back EMFs in the subspace $\alpha-\beta$ form a circle with $x=-1$ as plotted in Fig. 3b. However, the fourth-row vector is not orthogonal to the first-row vector anymore, but it does not affect the control of current in the new fundamental subspace due to the wye connection. Authors in [9], [10] apply the same transformation matrices as in [7], [8] but for a non-sinusoidal back-EMF PMSM. Because the fundamental 
components of currents interact with the third harmonic backEMFs, resulting in torque ripples. Therefore, a sliding mode control for speed is used. Nevertheless, the torque ripples as well as speed pulsation still exist.

\section{(3) Method 3}

In [11], [12], the new transformation matrix is proposed for a sinusoidal back-EMF five-phase PMSM according to (5) without an additional coefficient $x$ as in equation (12).

$\left[\boldsymbol{T}_{\text {Clarke }}^{3}\right]=\left[\begin{array}{cccc}\frac{\cos 0.5 \delta}{3.618} & \frac{\cos 2 \delta}{3.618} & \frac{\cos 2 \delta}{3.618} & \frac{\cos 0.5 \delta}{3.618} \\ \frac{\sin 0.5 \delta}{1.91} & \frac{\sin 2 \delta}{1.91} & \frac{-\sin 2 \delta}{1.91} & \frac{-\sin 0.5 \delta}{1.91} \\ \frac{\sin \delta}{5} & \frac{\sin 4 \delta}{5} & \frac{\sin 6 \delta}{5} & \frac{\sin 9 \delta}{5} \\ 1 & 1 & 1 & 1\end{array}\right]$

$\overrightarrow{e_{\alpha \beta z 0}} \cdot \overrightarrow{l_{\alpha \beta z 0}}=\vec{e}^{\prime} \cdot \vec{l}^{T}\left\{\left[\boldsymbol{T}_{\text {clarke }}^{3}\right]^{-1}\right\}^{T}\left[\boldsymbol{T}_{\text {clarke }}^{3}\right]^{T}={\overrightarrow{e^{\prime}}}^{\prime} \cdot \vec{l}^{T}$

$\overrightarrow{e_{\alpha \beta z 0}} \cdot \overrightarrow{l_{\alpha \beta z 0}}=\left\{\left[\boldsymbol{T}_{\text {clarke }}^{3}\right]^{-1}\right\}^{T} \overrightarrow{e^{\prime}} \cdot\left(\left[\boldsymbol{T}_{\text {clarke }}^{3}\right]{\overrightarrow{l^{\prime}}}^{T}\right.$

$\left[\begin{array}{l}e_{\alpha} \\ e_{\beta} \\ e_{z} \\ e_{0}\end{array}\right]=\left\{\left[\boldsymbol{T}_{\text {clarke }}^{3}\right]^{-1}\right\}^{T}\left[\begin{array}{l}e_{b} \\ e_{c} \\ e_{d} \\ e_{e}\end{array}\right]$

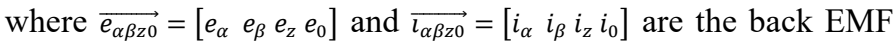
and current vectors in the new stationary subspaces respectively; $\overrightarrow{e^{\prime}}=\left[e_{b} e_{c} e_{d} e_{e}\right]$ and $\overrightarrow{i^{\prime}}=\left[i_{b}^{\prime} i_{c}^{\prime} i_{d}^{\prime} i_{e}^{\prime}\right]$ are the back EMF and current vectors in natural frame respectively.

All row vectors in equation (12) are orthogonal to one another when every row of matrix in equation (5) is modified. The first two row vectors are derived based on the current references in natural frame in [21] as shown in Fig. 4. The phasor angles of $c$ current and $d$-current are unchanged while those of phase $b$ and phase $e$ are shifted $0.5 \delta$ compared to the healthy case to compensate the loss of current in phase $a$. The same torque as in healthy mode can be preserved by increasing the amplitude of new current 1.382 times higher than the one in healthy mode.

In equation (12), the third-row vector is defined to guarantee its orthogonality to the first two row vectors and make sure that current $i_{z}$ is equal to zero. Constant coefficients in the denominators of all elements of $\left[\boldsymbol{T}_{\text {clarke }}^{3}\right]$ are determined to change the amplitude of the current references in natural frame. This adjusting enables the machine to generate a torque in faulty mode equal to healthy mode. Additionally, in [11], [12], the authors tackle the problem of the asymmetrical back EMFs in $\alpha-\beta$ frame as presented in [6] by changing the way to calculate the projection of back EMFs onto the new stationary frame $\alpha-\beta$ as shown in equations (13-15). Specifically, the transpose of the inversion of the new transformation matrix is applied instead of the transformation matrix. Indeed, the inversion of $\left[\boldsymbol{T}_{\text {clarke }}^{3}\right]$ is different form its transpose. In addition, equations (13-14) prove that the product of current and back-EMF vector in the new stationary subspaces is the same as in natural frame with a transformation in equation (15). However, the experimental result in [11], [12] contains high torque ripples since the back EMFs of the experimental machine include high harmonic components.

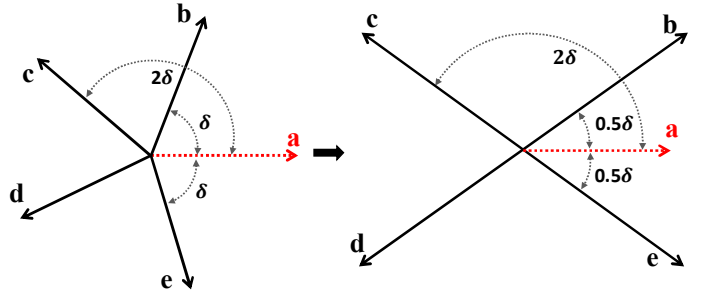

Fig. 4. New current references when phase $a$ is opened in method 3

(4) Method 4

In [13], a new transformation matrix applied for a sinusoidal back-EMF five-phase PMSM is expressed in equation (16). The principle is that the first two row vectors of the matrix in equation (5) are unchanged while its third-row vector is eliminated. In addition, elements of the fourth-row vector of (5) become 4 scalar variables $\left(k_{1}, k_{2}, k_{3}, k_{4}\right)$. These variables need to be estimated by using Particle Swarm Optimization, according to two optimization criteria. The first criterion, copper loss minimization resulting in unbalanced phase currents, is derived with $\left(k_{1}, k_{2}, k_{3}, k_{4}\right)=$ $(0.6328,-1,1,-0.6328)$. The other criterion with balanced phase currents is obtained when $\left(k_{1}, k_{2}, k_{3}, k_{4}\right)=(-1,1,-1,1)$.

$\left[\boldsymbol{T}_{\text {Clarke }}^{4}\right]=\frac{2}{5}\left[\begin{array}{cccc}\cos \delta & \cos (2 \delta) & \cos (2 \delta) & \cos (\delta) \\ \sin \delta & \sin (2 \delta) & -\sin (2 \delta) & -\sin (\delta) \\ k_{1} & k_{2} & k_{3} & k_{4} \\ 1 & 1 & 1 & 1\end{array}\right]$

Simulation results in [13] show that this method works with good performance when being applied to a purely sinusoidal machine.

(5) Method 5

In [14], the authors propose new transformation matrices for a non-sinusoidal back-EMF five-phase PMSM with an open phase. The healthy phases of the machine are imposed with nonsinusoidal current references to eliminate torque ripples. The transformation matrices for the fundamental components are the same as in [7]-[10] by using the matrix in equation (9) with $x=$ -1 . The new space for the fundamental currents and back EMFs is denoted as $\alpha_{1} \beta_{1} z_{1} 0_{1}$ to differ from the space for third harmonic components. The fundamental current and back EMFs in the new space are presented in Figs. 5a and 5b respectively.

The principle to find a new transformation matrix for the third harmonic components is like the fundamental ones. Thus, the MMF and back EMFs of the third harmonic components are expected to be the same as in healthy condition. Equations (17-18) present the conversions of the third harmonic currents and the third harmonic back EMFs from natural frame into the new space $\alpha_{3} \beta_{3} Z_{3} 0_{3}$ including the third harmonic plane $\alpha_{3}-\beta_{3}$, subspace $z_{3}$ $\left(i_{z 3}\right)$ and zero-sequence subspace $\left(i_{03}\right)$. Indeed, the new Clarke transformation matrix $\left[\boldsymbol{T}_{\text {clarke }}^{5}\right]$ in equation (19) is obtained by removing the first row of the matrix in equation (5). This row vector is associated to the first harmonic current $i_{\alpha 1}$ which is coupled with the third harmonic current $i_{\alpha 3}$. The second row of the matrix in (5), related to $i_{\beta 1}$, is remained and associated to a 
subspace called $z_{3}$. The third and fourth rows of the matrix in (5) associated to the third harmonic subspace $\alpha_{3}-\beta_{3}$ are reused. In equation (19), a coefficient $x$ is added to the row vector related to $\alpha_{3}$ to ensure the symmetrical characteristic of the third harmonic back-EMFs ( $x$ is equal to -1 ).

$$
\begin{aligned}
& {\left[\begin{array}{l}
i_{z 3} \\
\boldsymbol{i}_{\alpha 3} \\
\boldsymbol{i}_{\beta 3} \\
i_{03}
\end{array}\right]=\left[\boldsymbol{T}_{\text {clarke }}^{5}\right]\left[\begin{array}{l}
i_{b 3}^{\prime} \\
i_{c 3}^{\prime} \\
i_{d 3}^{\prime} \\
i_{e 3}^{\prime}
\end{array}\right] ; \quad\left[\begin{array}{l}
e_{z 3} \\
\boldsymbol{e}_{\alpha 3} \\
\boldsymbol{e}_{\beta 3} \\
e_{03}
\end{array}\right]=\left[\boldsymbol{T}_{\text {clarke }}^{5}\right]\left[\begin{array}{l}
e_{b 3} \\
e_{c 3} \\
e_{d 3} \\
e_{e 3}
\end{array}\right]} \\
& {\left[\boldsymbol{T}_{\text {clarke }}^{5}\right]=\frac{2}{5}\left[\begin{array}{cccc}
\sin \delta & \sin (2 \delta) & -\sin (2 \delta) & -\sin (\delta) \\
\cos 2 \delta+x & \cos \delta+x & \cos \delta+x & \cos 2 \delta+x \\
-\sin (2 \delta) & \sin \delta & -\sin (\delta) & \sin (2 \delta) \\
1 & 1 & 1 & 1
\end{array}\right]} \\
& {\left[\boldsymbol{T}_{\text {Park }}^{5}\right]=\left[\begin{array}{cccc}
0 & 0 & 0 & 0 \\
0 & \cos 3 \theta & \sin 3 \theta & 0 \\
0 & -\sin 3 \theta & \cos 3 \theta & 0 \\
0 & 0 & 0 & 1
\end{array}\right]}
\end{aligned}
$$

where $\left(i_{b 3}^{\prime}, i_{c 3}^{\prime}, i_{d 3}^{\prime}, i_{e 3}^{\prime}\right)$ are new third harmonic phase currents in natural frame; $\left(e_{b 3}, e_{c 3}, e_{d 3}, e_{e 3}\right)$ are the third harmonic components of back EMFs in natural frame; $\left(i_{\alpha 3}, i_{\beta 3}, i_{z 3}, i_{03}\right)$ and $\left(e_{\alpha 3}, e_{\beta 3}, e_{z 3}, e_{03}\right)$ are currents and back EMFs in the new space $\alpha_{3} \beta_{3} \mathrm{Z}_{3} 0_{3}$ respectively.

The third harmonic components of currents and back EMFs in the new space $\alpha_{3} \beta_{3} Z_{3} O_{3}$ are symmetrical as shown in Fig. 6 . Accordingly, the fundamental and third harmonic currents can be controlled independently, and their waveforms in natural frame are shown in Fig. 7. The total phase currents in natural frame are the sum of the corresponding first and third harmonic currents as presented in Figs. 8a. The non-sinusoidal back EMFs, with the third harmonic component equal to $32 \%$ of the first harmonic one, are presented in $8 \mathrm{~b}$. The ripple-free torque, when phase $a$ is opencircuited, is the same as the torque in healthy operation as plotted in Fig. 9a.

\section{Summary of studied methods}

When phase $a$ is open-circuited, types of the machines (related to back-EMF waveforms) have a strong effect on torque pulsations of the machines. The methods (1-4) in [6]-[13] propose only new transformation matrices for only fundamental components of currents and back EMFs.

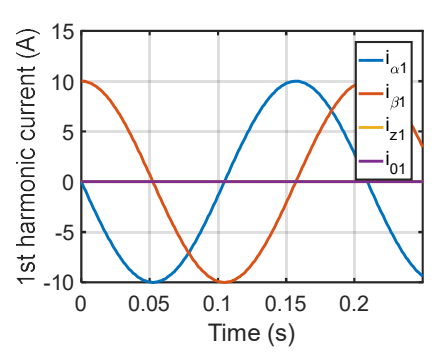

(a) (b)

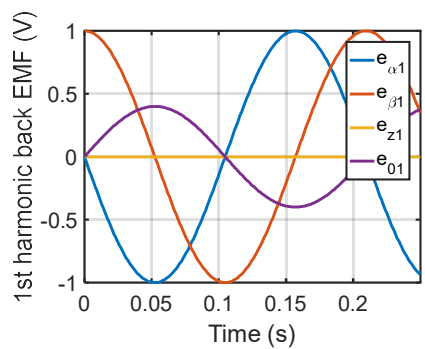

Fig. 5. The first harmonic components of current and back EMF in new stationary space $\alpha_{1} \beta_{1} z_{1} 0_{1}$ in method 5

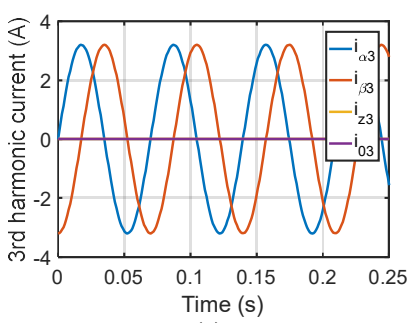

(a)

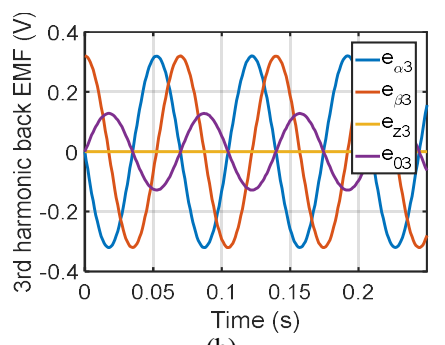

(b)
Fig. 6 . The third harmonics of current (a) and back EMF (b) in new stationary space $\alpha_{3} \beta_{3} Z_{3} 0_{3}$ in method 5

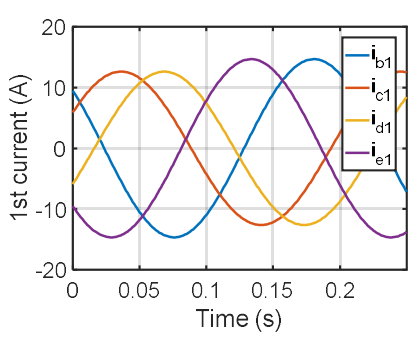

(a)

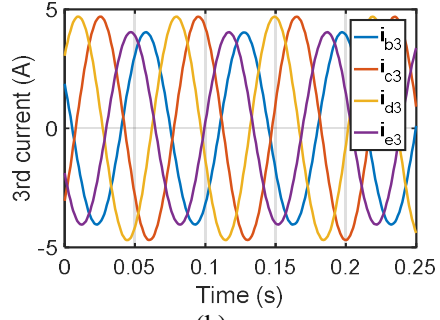

(b)
Fig. 7. The fundamental currents (a) and third harmonic currents (b) in natural frame at $10 \mathrm{rad} / \mathrm{s}$ in method 5

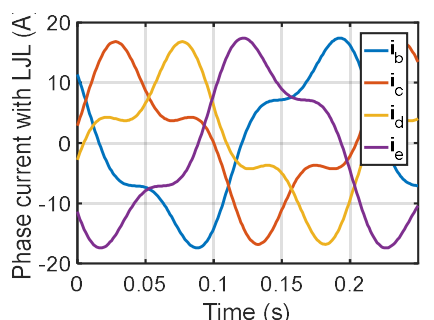

(a)

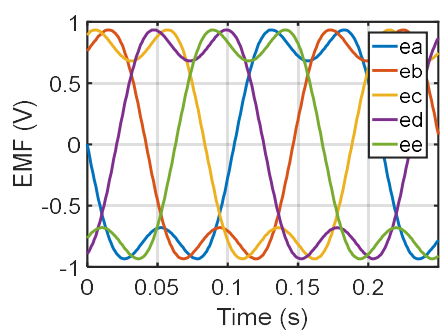

(b)
Fig. 8. Non-sinusoidal phase current references (a) and non-sinusoidal back EMFs (b) at $10 \mathrm{rad} / \mathrm{s}$ using method 5 when phase $a$ is opened

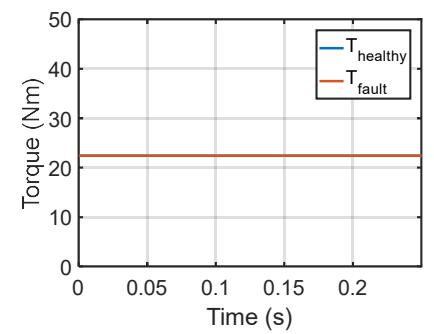

(a)

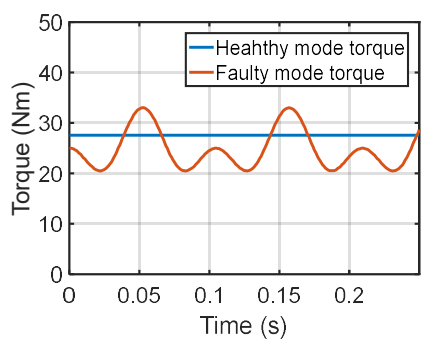

(b)
Fig. 9. Torques in healthy case and in single open phase fault with a nonsinusoidal back-EMF machine at $10 \mathrm{rad} / \mathrm{s}$ using method 5 (a) and using methods $(1-4)(b)$

If methods (1-4) in references [6]-[13] are applied for machines with non-sinusoidal back EMFs, the interactions between the fundamental harmonics of currents and the third and other high harmonic components of back EMFs will cause torque ripples as shown in Fig. 9b. Thus, in those papers, different control strategies are applied such as sliding mode control, remedial fieldoriented control and model predictive control to reduce the torque 
pulsations if the experimental back EMFs are not sinusoidal. However, the torque ripples still exist in these systems.

Only method 5 in [14] is able to solve the problem of third harmonic components theoretically by using new transformation matrices for the third harmonic components as discussed in the previous subsection. However, the experimental results show that torque ripples are produced in [14] with single open phase fault. The presence of torque ripples can be explained by the control of non-constant current references in $\mathrm{d}-\mathrm{q}$ frame at high speed or the existence of other high harmonic components of back EMFs in the experimental machine.

In all studied methods above, the current in subspace $z\left(i_{z}\right)$ is used for optimization criteria or torque ripple elimination. Criterion Lowest Jules Losses (LJL) results in minimizing copper losses in which the amplitudes of phase currents are different in healthy phases. With criterion Equal Jules Losses (EJL), copper losses are distributed equally in every phase and healthy phase currents have the same amplitude. Using these methods, the new transformation matrices need to be determined for each case of open phase fault. For example, a new transformation matrix for open phase fault in phase $a$ is unable to be applied for an open phase fault in phase $b, c, d$ and $e$, and vice versa. As a result, the calculations and data storage will be challenges in practical applications.

\section{CONCLUSIONS}

The paper has given an overview of several methods using reduced-order transformation matrices for fault-tolerant control for a five-phase machine in single open phase fault. The paper has analyzed the basic ideas and strategies to find the new transformation matrices. With methods (1 to 4) in [6]-[13], the fundamental components of current and back EMFs are considered to obtain constant torque. However, these methods are no longer suitable for non-sinusoidal back EMF machines due to torque ripples. The fifth method in [14] proposes the new transformation matrices for non-sinusoidal back EMFs. Thus, non-sinusoidal current references are taken into account to produce a ripple-free torque. This method has high potential to apply to all non-sinusoidal back-EMF multiphase machines with a certain number of phases. However, a drawback of all methods above is that a new matrice need to be defined for a specific open phase fault.

\section{REFERENCES}

[1] E. Levi, "Multiphase Electric Machines for Variable-Speed Applications," IEEE Transactions on Industrial Electronics, vol. 55, no. 5, pp. 1893-1909, May 2008.

[2] J. Huang, M. Kang, J. q. Yang, H. b. Jiang, and D. Liu, "Multiphase machine theory and its applications," in 2008 International Conference on Electrical Machines and Systems, 2008, pp. 1-7.

[3] F. Barrero and M. J. Duran, "Recent Advances in the Design, Modeling, and Control of Multiphase Machines-Part I," IEEE Transactions on Industrial Electronics, vol. 63, no. 1, pp. 449-458, Jan. 2016.

[4] M. J. Duran and F. Barrero, "Recent Advances in the Design, Modeling, and Control of Multiphase Machines-Part II," IEEE Transactions on Industrial Electronics, vol. 63, no. 1, pp. 459-468, Jan. 2016.
[5] Jen-Ren Fu and T. A. Lipo, "Disturbance-free operation of a multiphase current-regulated motor drive with an opened phase," IEEE Transactions on Industry Applications, vol. 30, no. 5, pp. 1267-1274, Oct. 1994.

[6] Hyung-Min Ryu, Ji-Woong Kim, and Seung-Ki Sul, "Synchronous-frame current control of multiphase synchronous motor under asymmetric fault condition due to open phases," IEEE Transactions on Industry Applications, vol. 42, no. 4, pp. 1062-1070, Aug. 2006.

[7] H. Guzmán, M. J. Durán, and F. Barrero, “A comprehensive fault analysis of a five-phase induction motor drive with an open phase," in 2012 15th International Power Electronics and Motion Control Conference (EPE/PEMC), 2012, p. LS5b.3-1.

[8] H. Guzman et al., "Comparative Study of Predictive and Resonant Controllers in Fault-Tolerant Five-Phase Induction Motor Drives," IEEE Transactions on Industrial Electronics, vol. 63, no. 1, pp. 606-617, Jan. 2016.

[9] B. Tian, Q. T. An, J. D. Duan, D. Y. Sun, L. Sun, and D. Semenov, "Decoupled Modeling and Nonlinear Speed Control for Five-Phase PM Motor Under Single-Phase Open Fault," IEEE Transactions on Power Electronics, vol. 32, no. 7, pp. 5473-5486, Jul. 2017.

[10] B. Tian, Q. T. An, J. D. Duan, D. Semenov, D. Y. Sun, and L. Sun, "Cancellation of Torque Ripples With FOC Strategy Under Two-Phase Failures of the Five-Phase PM Motor," IEEE Transactions on Power Electronics, vol. 32, no. 7, pp. 5459-5472, Jul. 2017.

[11] H. Zhou, W. Zhao, G. Liu, R. Cheng, and Y. Xie, "Remedial Field-Oriented Control of Five-Phase Fault-Tolerant Permanent-Magnet Motor by Using Reduced-Order Transformation Matrices," IEEE Transactions on Industrial Electronics, vol. 64, no. 1, pp. 169-178, Jan. 2017.

[12] H. Zhou, G. Liu, W. Zhao, X. Yu, and M. Gao, "Dynamic Performance Improvement of Five-Phase Permanent-Magnet Motor With Short-Circuit Fault," IEEE Transactions on Industrial Electronics, vol. 65, no. 1, pp. 145 155, Jan. 2018.

[13] A. Seck, L. Moreau, M. F. Benkhoris, and M. Machmoum, "Automatic generation of optimal phase currents for five-phase PMSG control under open phase condition," in IECON 2017 - 43rd Annual Conference of the IEEE Industrial Electronics Society, 2017, pp. 3847-3852.

[14] G. Liu, Z. Lin, W. Zhao, Q. Chen, and G. Xu, "Third Harmonic Curren Injection in Fault-Tolerant Five-Phase Permanent-Magnet Motor Drive," IEEE Transactions on Power Electronics, vol. PP, no. 99, pp. 1-1, 2017.

[15] L. Parsa and H. A. Toliyat, "Fault-tolerant five-phase permanent magnet motor drives," in Conference Record of the 2004 IEEE Industry Applications Conference, 2004. 39th IAS Annual Meeting., 2004, vol. 2, pp. 1048-1054 vol.2.

[16] E. Semail, X. Kestelyn, and A. Bouscayrol, "Right harmonic spectrum for the back-electromotive force of an n-phase synchronous motor," in Conference Record of the 2004 IEEE Industry Applications Conference, 2004. 39th IAS Annual Meeting., 2004, vol. 1, pp. 1-78.

[17] X. Kestelyn, E. Semail, and J. Hautier, "Vectorial multi-machine modeling for a five-phase machine," presented at the International Congress on Electrical Machines (ICEM'02), 2002.

[18] E. Semail, A. Bouscayrol, and J.-P. Hautier, "Vectorial formalism for analysis and design of polyphase synchronous machines," Eur. Phys. J. AP, vol. 22 , no. 3 , pp. 207-220, Jun. 2003.

[19] L. Parsa and H. A. Toliyat, "Five-phase permanent-magnet motor drives," IEEE Transactions on Industry Applications, vol. 41, no. 1, pp. 30-37, Feb. 2005.

[20] F. Locment, E. Semail, and X. Kestelyn, "Vectorial Approach-Based Control of a Seven-Phase Axial Flux Machine Designed for Fault Operation," IEEE Transactions on Industrial Electronics, vol. 55, no. 10, pp. 3682-3691, Oct. 2008.

[21] G. Liu, L. Qu, W. Zhao, Q. Chen, and Y. Xie, "Comparison of Two SVPWM Control Strategies of Five-Phase Fault-Tolerant Permanent-Magnet Motor," IEEE Transactions on Power Electronics, vol. 31, no. 9, pp. 6621-6630, Sep. 2016. 